\title{
Guillermo Arriaga. El relato fronterizo
}

\section{Guillermo Arriaga. The Border Story}

\author{
GABRIEL RÓDENAS \\ Universidad de Murcia \\ gabriel.rodenas@um.es \\ ORCID ID: 0000-0002-9333-4266
}

\begin{abstract}
Resumen: La figura de Guillermo Arriaga supone un caso atípico dentro del panorama narrativo contemporáneo. Novelista, cineasta y escritor de los libretos de películas como Amores Perros, 21 Gramos, Babel o Los tres entierros de Melquiades Estrada, Arriaga nos ofrece una panorámica de lo que podría denominarse el «relato fronterizo», así como una lectura razonada de los límites de la adaptación. A través del análisis de su obra tanto fílmica como literaria, así como de sus propias declaraciones y de los escasos trabajos académicos sobre su obra que a fecha de hoy existen, pretendemos aportar algo de luz sobre el fenómeno de la adaptación, el remake, y sus peculiaridades.
\end{abstract}

Palabras clave: adaptación, remake, relato fronterizo, variación, guion, formatos.

\begin{abstract}
The figure of Guillermo Arriaga supposes an atypical case within the contemporary narrative panorama. Novelist, filmmaker and writer of the librettos of films like Amores Perros, 21 Grams, Babel or The three burials of Melquiades Estrada, Arriaga offers an overview of what could be denominated the border story, as well as a reasoned reading of the limits of the adaptation. Through the analysis of his work both film and literary, as well as his own statements, we intend to bring some light on the phenomenon of adaptation, the remake and their peculiarities.
\end{abstract}

Keywords: adaptation, remake, border story, variation, script, formats. 


\section{INTRODUCCIÓN}

Sin duda, Guillermo Arriaga constituye una figura clave en el panorama narrativo contemporáneo. La calidad de sus trabajos (ampliamente reconocida), así como su repetida negativa a ser considerado un guionista (él prefiere la denominación de escritor), lo convierten en uno de los máximos exponentes contemporáneos en el arte de contar historias. Su privilegiada posición de cineasta, autor de libretos para cine y novelista le permite llevar a cabo una reflexión sopesada, razonada e ilustrada de las peculiaridades de la adaptación, así como de las diversas alteraciones y variaciones a que se ve sometido un guion.

Al tratarse de distintos formatos (del papel al celuloide, por ejemplo), no podemos considerar la conversión de los textos de Arriaga como remakes. Bien es cierto que esta circunstancia elimina casi por completo la posibilidad de transcripción exacta de un texto a otro, como sí puede hacerlo el cine, con mayor o menor acierto. Véase el caso del remake plano a plano que Gus Van Sant realizó en 1998 de la célebre obra de Hitchcock Psycho (1960). Pero plantea otras cuestiones no menos relevantes (y potencialmente aplicables al remake): ¿Qué podemos modificar manteniendo la identidad de la obra? ¿Todos los textos son susceptibles de adaptación cinematográfica? ¿Todas las películas pueden convertirse en novela?

Estas y otras preguntas cruzan la trayectoria del mexicano. Nuestro objetivo en el presente artículo es dar forma a esa problemática existente en la obra de Guillermo Arriaga, contribuyendo, por una parte, a aportar material para futuras investigaciones sobre su trabajo, para facilitar la comprensión del mismo y para aclarar algunas cuestiones referentes al fenómeno de la adaptación y las transformaciones de un texto.

\section{Del PAPEl al Celuloide}

Contrariamente a lo que suele pensarse, Guillermo Arriaga inició su andadura como escritor de novelas. Antes de los libretos de Amores perros (González Iñárritu, 2000), 21 Gramos (González Iñárritu, 2004) o Babel (González Iñárritu, 2006), Arriaga ya contaba con una carrera literaria a sus espaldas. Al Escuadrón Guillotina (1991), le siguieron Un dulce olor a muerte (1994), llevada al cine en 1999 de la mano de Gabriel Retes, y El búfalo de la noche (1994), posteriormente dirigida por Jorge Hernández Aldana en 2007. No serían las últimas incursiones del autor de El salvaje (2016) en el universo de la literatura, escenario que ya hemos examinado en otro lugar (Ródenas, 2016).

Aunque los problemas de adaptación presentan sus propias características, comparten algunos elementos con la traducción 
literaria, tal y como se desprende del estudio de la traductora de $U n$ dulce olor a muerte al rumano (Petrescu, 2011). De acuerdo con Petrescu, «traducir significa desplazar espiritualmente la obra de una cultura específica hasta otra cultura de acogida, fenómeno que supone una especie de traslado de elementos lingüísticos, culturales, sociales y antropológicos» (2011: 142). ¿Qué sucede cuando tratamos de adaptar un texto de un formato a otro? ¿No nos enfrentamos a un reto mayor si cabe?

Salvo en el caso del remake extremo (el citado ejemplo del Psycho de Gus Van Sant), que a la postre supone poco más que una actualización estilística y fotográfica de la obra anterior, tanto la adaptación de un formato a otro - del papel a la pantalla- como las nuevas versiones deben hacer frente a una serie de preguntas del tipo: ¿Qué dejar? ¿Qué quitar? ¿Qué modificar?

Contamos con muchas pistas sobre la insistencia de Arriaga en diferenciar su obra literaria de la cinematográfica; sus novelas de sus libretos: sus «novelas son anticinematográficas. El guión es distinto: es sólo visual» (Enrigue, 2007: 49). Mientras que él ha reconocido la práctica imposibilidad de adaptar una novela como El salvaje (2016) al cine -rechazando las diversas ofertas que le han propuesto-, otros trabajos suyos, como Amores perros, adoptaron su forma adecuada tras varios intentos fallidos de nacer en forma de novelas; dos novelas en el caso de Amores perros (Enrigue, 2007: 49). Aunque en sus libretos el resultado es coherente con la idea de Arriaga según la cual el cine debe ser stendhaliano, más centrado en la acción y en el avance de la historia, la literatura (su literatura) permite explorar la interioridad de los personajes desde otro ángulo, desde otra perspectiva. Evidentemente, sí se podría adaptar El salvaje a la gran pantalla, tal y como ha sucedido con otras novelas suyas, pero en este caso la sensación de "pérdida" probablemente sería mayor.

¿Es posible adaptar a Faulkner o Joyce al cine? Sí, siempre que se esté dispuesto a acentuar en el receptor esa posible sensación de "pérdida". A fin de que el lector pueda contrastar esta opinión, puede revisar la adaptación del clásico de Faulkner Mientras agonizo que realizó James Franco: As I Lay Dying (2013). No es el único intento, siempre fallido, de llevar a Faulkner a la gran pantalla. En cambio, hay escritores, como Barry Gifford, cuyo estilo esquemático, visual $\mathrm{y}$, en ocasiones, poco introspectivo se presta a ser filmado. Lo mismo sucede con el thriller y la novela negra, por poner dos géneros evidentes. ¿Se desprende de esta afirmación que la introspección no cabe el cine? Indudablemente, no de forma categórica, pues hay notables piezas en ese sentido: 8 y medio (Fellini, 1963), Pasión (Bergman, 1969), El espejo (Tarkovski, 1975), Sacrificio (Tarkovski, 
1986), Mulholland Drive (Lynch, 2001) o INLAND EMPIRE (Lynch, 2006), etc.

Ahora bien, frente al tipo de cine denominado símplex -por utilizar el término empleado por Lipovetsky y Serroy en La pantalla global (2009)-, la literatura permite más el juego con la narración múltiplex (Orellana, 2012: 1158). Esto no quita que existan también buenos ejemplos de múltiplex en cine, como Amores perros, 21 gramos, Babel, Vidas cruzadas (Altman, 1993, basada en los relatos de Raymond Carver), Pulp Fiction (Tarantino, 1994), Magnolia (Anderson, 1999) o Crash (Haggis, 2004), por mencionar unos pocos trabajos bien conocidos.

Respecto al modo en que Arriaga afronta el guion, cabe señalar el sesgo literario del mismo, aunque intente demarcarse de él. A esto nos referimos cuando hablamos del relato fronterizo, aquel que se sitúa en el límite entre el cine y la literatura:

\section{¿El guión es entonces una pieza literaria?}

Yo es lo que procuro: pongo tanto cuidado en el lenguaje y la estructura que lo veo como literatura. Lo que he procurado es, precisamente, llevar estructuras literarias al cine (Enrigue, 2007: 48).

O en la misma línea:

¿Cuál es la diferencia definitiva entre un guión y una obra de cine?

Un guionista concede, su trabajo es conceder y copiar. Un escritor de cine concilia. Concilia las necesidades de la película con el mundo que escribió, pero es un mundo completo - estética y moralmente complejo- concebido con mucho cuidado (Enrigue, 2007: 50).

En este sentido, para que los universos literario y cinematográfico se combinen de un modo efectivo, es necesario que el director comparta una similar visión del mundo con el escritor, unos gustos afines. De lo contrario, la empresa podría fracasar de manera estrepitosa. Tal fue la experiencia que Arriaga tuvo con la adaptación de El búfalo de la noche y Un dulce olor a muerte, así como la que posteriormente provocaría la realización de Babel.

Esta última aventura nos permite introducir el siguiente apartado: el guion y sus avatares.

\section{UN CINE MUY LITERARIO}

Dentro de la claramente delimitada obra de Arriaga, el guionlibreto ocupa un papel central. Confesada su impronta literaria, podemos aproximarnos a ella atendiendo a esa doble dimensión. 
Tal vez, algún lector o lectora estime que, una vez adquirido por una productora, el guion permanece intocable. La realidad es que las vicisitudes que debe sufrir un libreto antes de convertirse en imagen son diversas: desde la cancelación del proyecto a la modificación del texto original.

Guillermo Arriaga es autor de algunas de las obras para cine más notables de los últimos tiempos. Su exploración de nuevas formas de narratividad así como del alma humana lo convierten en un contador de historias sobresaliente. No vamos a hacer un repaso de toda su producción en este campo, y nos centraremos en el análisis de algunos aspectos del catálogo. Lo que nos interesa en el presente contexto es ilustrar hasta qué punto una obra orientada a su filmación puede (y suele ser) revisada del mismo modo que una pieza literaria.

Ya hemos señalado que Amores perros surgió de la imposibilidad de escribir dos novelas. Por decirlo de otro modo, aquellas historias se desarrollaban mejor en formato cinematográfico que literario, lo cual no quiere decir que en Amores perros no haya mucha literatura, especialmente Faulkner. Mucho Faulkner. Y Stendhal.

El guion de la primera colaboración con Alejandro González Iñárritu conoció treinta y tres versiones (Orellana, 2012: 1163). Por su parte, 21 gramos - probablemente su libreto más complejo y faulkneriano- contó con nada menos que setenta y dos versiones (Orellana, 2012: 1164). A modo de apunte, cabe señalar que la vinculación entre la obra de Arriaga y la de Faulkner es un rasgo que no pasa desapercibido a ningún estudioso (véase Carbajosa, 2014).

En la que sería la penúltima obra realizada entre los dos mexicanos, la creciente impronta literaria del trabajo fílmico de Arriaga, así como la reclamación de mayor protagonismo o reconocimiento de autoría en la figura del escritor, marcarán el creciente distanciamiento entre los puntos de vista de los dos creadores, que culminaría en la ruptura tras Babel.

En 21 gramos el peso de la literatura se incrementa, aunque, en su origen, se concibió como una novela que fue reescrita para ver la luz en forma de guion (Sorrento, 2010). Además de la estructura inspirada en el autor de El ruido y la furia, encontramos elementos como un ejemplar de Cruzando el paraíso de Sam Shepard (1997) y el poema de Eugenio Montejo «La tierra giró para acercarnos». La intensificación literaria en el trabajo de Arriaga, entre otros aspectos, contribuyó a alejar los universos creativos de ambos autores. Iñárritu estaba en ese momento interesado en las historias que se desarrollaban entre diversos lapsos temporales, pero después de la «Trilogía de la muerte», escritor y director tomaron dos caminos que se bifurcaban en un bosque amarillo. El sesgo del resto de la posterior 
producción del director de Birdman (González Iñárritu, 2014), con el irregular punto intermedio que supuso Biutiful (González Iñárritu, 2010), dejó bien claro que Iñárritu seguiría otros derroteros a través de los cuales cosecharía no pocos éxitos.

El caso de Babel supuso el distanciamiento definitivo entre los dos colaboradores. No pretendemos entrar en las cuestiones personales que hubieran podido propiciar el cisma. Nos interesa más prestar atención a algunos de los cambios a los que fue sujeto el libreto y a la reflexión sobre el papel del escritor (autor) en la historia, lo que entronca con el rechazo de Arriaga haciael término guionista: el novelista dibuja un universo completo y no solo una estructura, una guía o un esqueleto que el director deba completar. De ahí que algunos escritores -sin demasiado efecto- reclamen su presencia en el proceso de producción (para así poder señalar tiros de cámara, puntos de vista o localizaciones, por ejemplo). Normalmente, esto suele ser muy mal acogido por parte de director y productores.

Algunas disputas por la naturaleza ética y estética de un proyecto son ya harto conocidas y, en ocasiones, contribuyen a consolidar la carrera de las partes implicadas. Pensamos, por ejemplo, en la polémica odisea de Asesinos natos (Stone, 1994), de cuyo resultado Tarantino, autor del guion original, se desvinculó por completo.

Por lo que respecta a las modificaciones del texto original de Babel, podemos señalar que la historia que se desarrolla en Japón, protagonizada por una chica sordomuda, tenía lugar en España. La chica perdía la vista en la versión inicial.

Para concluir este apartado, queremos mencionar un detalle de la obra con la que Guillermo Arriaga se alzó con el premio al mejor guion en Cannes, 2005. Nos referimos a Los tres entierros de Melquiades Estrada, dirigida y protagonizada por Tommy Lee Jones. Con una estructura en apariencia más sencilla que las anteriormente citadas, la cinta ostenta una notable carga literaria: de Homero al Quijote, de los fantasmas de Juan Rulfo al Mientras agonizo de William Faulkner.

Sin duda, la apuesta que hace Arriaga por un cine literario que no caiga en la mera contemplación, que asuma la impronta stendhaliana de la acción y se centre en el avance de la historia, es clara y sólida.

\section{Al otro lado de la cámara. El cine de Guillermo Arriaga}

La faceta más estrictamente cinematográfica de Guillermo Arriaga abarca las facetas de director y productor. Autor de varios cortometrajes -muy sugerentes El pozo (2010) y Broken Night (2013)-, del largo The Burning Plain (2008) y de la antología Words with God (2014, con la participación de Emir Kusturica, Álex de la Iglesia, Hideo 
Nakata, Amos Gitai y Mira Nair, entre otros), también contribuyó con una pieza al trabajo colaborativo Rio, I Love You (2014).

Como productor, además de participar en las adaptaciones de sus novelas, así como en Amores perros y 21 gramos, ha intervenido en diversos cortos y en el largometraje del director venezolano Lorenzo Vigas, Desde allá (2015), ganadora del León de oro en el Festival Internacional de Cine de Venecia de 2015, entre otros premios.

The Burning Plain, traducida al castellano como Lejos de la tierra quemada, acentúa el sesgo literario de la concepción que Arriaga tiene del cine, y que es el objetivo de nuestro análisis ${ }^{1}$ :

If you see The Three Burials, it has nothing to do with Amores Perros, [and] the structure to The Burning Plain is very different from the structure of 21 Grams. Each story has a different way to be tolda great lesson by Faulkner (Arriaga a Sorrento, 2010).

A pesar de ello, tal y como iremos viendo, sí encontramos ciertas resonancias entre The Burning Plain y 21 gramos. Las hay tanto de tipo formal como temático. Asimismo, hallamos muchos elementos presentes en ambas obras ( $\mathrm{y}$ en otras surgidas de su pluma). The Burning Plain, salvo por el plano inicial de un incendio en mitad del desierto, comienza del mismo modo que 21 gramos: con un plano con ligero contraluz, en una habitación indeterminada donde aparecen dos personajes - un hombre y una mujer- cuya relación es ambigua o imprecisa. En ambos trabajos, la verdadera acción, el nudo, se inicia con un accidente. Hospitales y moteles son escenarios de las dos películas (y de casi toda su producción). La muerte también está presente en todas ellas. La infidelidad, los celos, la promiscuidad, pero también la fraternidad y los lazos paterno-filiales son lugares comunes dentro del universo diseñado por Arriaga. La cicatriz cruzará tanto 21 gramos como The Burning Plain, así como su novela El salvaje. No obstante, tanto en 21 gramos como en The Burning Plain, Guillermo Arriaga nos ofrece una metáfora de la esperanza, del cambio (la migración), de unidad dentro del caos, de fraternidad. Nos referimos a la bandada de pájaros.

Sin lugar a dudas, The Burning Plain recoge muchos de los temas y aspectos que Guillermo Arriaga desarrolla en sus novelas y muchos de sus guiones. No es nuestra intención, empero, realizar una exégesis completa de su obra. Sí queremos señalar la acentuación literaria presente en esta pieza. Del mismo modo, Lejos de la tierra

\footnotetext{
${ }^{1}$ Quien desee otro tipo de aproximación al filme, puede consultar Sorrento (2010) o Tomas Maier (2009).
} 
quemada muestra un curioso ejercicio de adaptación (o contaminación), concretamente de algunos momentos de El ruido y la furia de Faulkner (Sorrento, 2010). ¿Acaso el personaje de Marian/Sylvia, interpretado en distintas franjas temporales por Charlize Theron y Jennifer Lawrence, no es sino la Caddy del relato faulkneriano?

Por último, desde nuestro punto de vista, esta película evoca a Paris, Texas (Wenders, 1984), escrita por Sam Shepard, un autor con una trayectoria similar a la del mexicano, si bien, en el filme que nos ocupa, el cierre - tal y como suele suceder en los trabajos de Arriagatiene un carácter más esperanzador.

\section{CONClusiones}

En este trabajo, hemos intentado estudiar la propuesta narrativa de Guillermo Arriaga tomando como referencia algunas de sus novelas, libretos y piezas cinematográficas. Tal y como señalamos en la introducción, el suyo es un caso límite, fronterizo, pero extremadamente apropiado para ilustrar los problemas que queríamos examinar en el presente trabajo. A lo largo de estas páginas, confiamos en haber ofrecido suficientes argumentos que prueben nuestra afirmación.

Del análisis de sus obras se desprenden algunas peculiaridades a las que se ven sujetos tanto remakes como adaptaciones varias. A través de su trabajo y sus palabras, Arriaga nos ofrece numerosas pistas y claves para entenderlas. Siempre procediendo con cautela, y sabedores de los numerosos contraejemplos que podemos encontrar, hemos planteado que no todas las novelas son susceptibles de trasladarse al celuloide (o al píxel) sin provocar una cierta sensación de pérdida. Mientras que el cine se nos presenta como un formato o medio más adecuado para realizar remakes puros ${ }^{2}$, la literatura podría considerarse, en cierto modo, un medio más sofisticado para abordar, por ejemplo, el diálogo interior o el flujo de los pensamientos, al menos si tomamos como referencia el cine símplex, de acuerdo con el término propuesto por Lipovetsky y Serroy (2009), y si advertimos además que hay muchos casos de cine múltiplex, como hemos ejemplificado, de manera que los dos terrenos artísticos pueden equipararse en cuanto a sus posibilidades expresivas.

Del mismo modo, evocando de nuevo los casos de Amores perros o 21 gramos, no todas las películas/libretos son susceptibles de brillar

\footnotetext{
${ }^{2}$ Huelga decir que existen remakes literarios, pero no caen dentro del campo de nuestros intereses en este trabajo. Por lo demás, dentro del ámbito literario, el remake absoluto no es posible, salvo para el ficticio Pierre Menard de Borges.
} 
en forma de novela. La necesidad del elemento audiovisual, el ritmo de la narración, la inclinación por un esquema más stendhaliano y otros factores influyen en el producto final.

Al igual que otros investigadores e investigadoras, hemos apuntado la estrecha conexión entre los trabajos de Arriaga y los de Faulkner, no solo por las cuestiones de estilo y modos de estructurar la historia, sino porque ambos autores ofrecen ejemplos sobre los límites de la adaptación y el remake (amén de que el propio Arriaga ha confesado su influencia en diversas entrevistas). Los dos, Arriaga y Faulkner, guardan una estrecha relación con el cine: el propio Faulkner adaptó El sueño eterno (1946) y Tener y no tener (1944) a fin de que fuesen rodadas por su amigo Howard Hawks. No serían las únicas colaboraciones entre escritor y cineasta ni las únicas incursiones del autor de Las palmeras salvajes en la industria cinematográfica.

Curiosamente, los trabajos de Arriaga resultan más faulknerianos conforme se alejan del formato novela (salvo, tal vez, en El salvaje). Se advierte en la «Trilogía de la muerte»y, por supuesto, alcanza su paroxismo en The Burning Plain.

Más allá de las lecturas semióticas e interpretativas y del análisis literario o fílmico, nos atrevemos a sugerir que el trabajo de Arriaga conforma una suerte de universo transmedia. Al igual que sucede con The Matrix (Lana y Lilly Wachowski, 1999) -examinado por Henry Jenkins en su interesante Convergence Culture (2006)-, aunque de un modo más sutil, Guillermo Arriaga va construyendo su propio Yoknapatawpha, el condado ficticio creado por Faulkner. La diferencia reside en que el territorio Arriaga se expande de manera progresiva a lo largo de su obra hasta cubrir (al menos potencialmente) todo el globo, toda la humanidad. A lo largo de novelas, guiones y películas, el mexicano va diseminando elementos que contribuyen a que veamos su obra como un todo, donde todos los elementos se hallan conectados, aunque el lector/espectador solo pueda percibirlo de un modo inicialmente fragmentario.

Mediante estos apuntes, esperamos haber aportado algo más de luz sobre la conexión entre literatura y cine. Asimismo, hemos tratado de contribuir desde una perspectiva académica al estudio del trabajo de Guillermo Arriaga, uno de los exploradores más interesantes de las nuevas formas de narrativa contemporánea al que, a nuestro juicio, todavía no se ha hecho debida justicia.

\section{Bibliografía CITADA}

Arriaga, Guillermo (1991), Un dulce olor a muerte, México, Planeta México. 
Arriaga, Guillermo (1994), El búfalo de la noche, México, Planeta México.

Arriaga, Guillermo (2000), Amores perros, Barcelona, Verticales/Norma Editorial [2007].

Arriaga, Guillermo (2004), 21 gramos, Barcelon, Verticales/Norma Editorial [2007].

Arriaga, Guillermo (2006), Retorno 201, Barcelona, Verticales/Norma Editorial.

ArRiaga, Guillermo (2016), El salvaje, Barcelona, Alfaguara.

CARbajosa, Mónica (2014), «La dislocación temporal: análisis del relato "Una rosa para Emily", de William Faulkner, y del largometraje 21 gramos de Alejandro González Iñárritu», en P. J. Pardo y J. Sánchez Zapatero (eds.), Sobre la adaptación y más allá: trasvases filmoliterarios, Universidad de Salamanca, págs. 247-254.

EnRigue, Álvaro (2007), «El nicho de Arriaga», Letras libres, 100, págs. 48-50.

Jenkins, Henry (2006), Convergence Culture, Barcelona, Paidós.

LipOVETSKY, Gilles y Jean Serroy (2009), La pantalla global, Barcelona, Anagrama.

Orellana, Juan (2012), «Las mixtificaciones narrativas en el cine de Alejandro González Iñárritu», Comunicación: Revista Internacional de Comunicación Audiovisual, Publicidad y Estudios culturales, 10, págs. 1158-1171.

Petrescu, Olivia N. (2011), «La traducción de los culturemas (Discusión al margen de la traducción de una novela de Guillermo Arriaga)», Valenciana, 8, págs. 139-172.

RódenAS, Gabri (2016), «Conexión Arriaga», Zenda [En línea: http: / / www.zendalibros.com/conexion-arriaga/].

Sorrento, Matt (2010), «Writing (and Filming) the memories: An interview with Guillermo Arriaga on The Burning Plain», Bright Light Film Journal [En línea: http://brightlightsfilm.com/writingand-filming-the-memories-an-interview-with-guillermo-arriagaon-the-burning-plain/\#].

TOMAs MAIER, Alejandra (2011), «Camino a la redención: la tragedia en el cine para la transmisión ficcionada», Ética y cine. Congreso Online 2011 [En línea: http://www.eticaycine.org/Camino-a-laredencion].

Fecha de recepción: 03/06/2019.

Fecha de aceptación: 25/07/2019. 